\title{
O TEMOR DA RESSIGNIFICAÇÃO DO TEMA FINANCIAMENTO PÚBLICO EDUCACIONAL NO ATUAL CENÁRIO BRASILEIRO
}

The fear of the resignification of the theme Public

Education Funding in the current Brazilian scenario

Bocchi, Roberta Maria Bueno

robertabocchi66@gmail.com 


\title{
RESUMO
}

O Financiamento Público Educacional constitui um espaço de disputa de poder, onde a parte mais fraca é aquela que se cala, a dos financiados. No atual cenário brasileiro de recessão financeira anunciada, é urgente a reflexão sobre as questões que envolvem esse tema, do contrário, corremos o risco de perder recursos financeiros que, até então, após um histórico de luta, estiveram presentes no orçamento público das diversas esferas governamentais. Nesse contexto, aprofundase, aqui, essa discussão, levantando-se alguns aspetos históricos, orçamentários e educacionais e propondo uma reflexão crítica sobre o tema. Busca-se caracterizar a questão do Financiamento Público como um dos principais pilares de sustentação para uma educação pública capaz de combater o imobilismo que se instalou entre o poder dominante e os financiados e erguer uma bandeira revolucionária de discussão sobre o tema aqui proposto e sua responsabilidade com a Educação Básica Pública, vista como um ato político.

PALAVRAS-CHA VE: Financiamento da Educação Pública. Escola Pública. Educação.

\begin{abstract}
Public Education Funding constitutes an area with dispute of power, where the weakest part, the financed, are the ones that have no say. In the current Brazilian scenario of the financial recession, it is a matter of urgency to reflect on the issues that are involved in this theme, otherwise we run the risk of losing financial resources that until then, after a history of struggle, was present in the public budget of various governmental spheres. In this context, we deepen this discussion, raising some historical, budgetary and educational aspects and propose a critical reflection on the theme. The aim is to characterize the theme of Public Funding as one of the main pillars of support for a public education able to combat the immobility that settled between the dominant power and the financed and to raise a revolutionary banner of discussion on the subject proposed here and its responsibility with Public Basic Education, seen as a political act.
\end{abstract}

KEYWORDS: Public Education Funding. Public School. Education. 


\section{Introdução}

É desafiador escrever este texto, levando em consideração o título que o acompanha, sem abeirar a indignação acadêmica e cidadã. Por isso, é fundamental escrevê-lo, mesmo porque falar sobre o financiamento público das escolas públicas brasileiras nunca foi tão necessário como agora. Momento marcado por perdas de direitos humanos há tanto tempo conquistados; crises financeiras anunciadas em tom de catástrofe; discursos políticos polarizados por uma população sem paciência e tempo para a reflexão, impulsionados por políticos amedrontados pelo fantasma de esquemas de corrupção, sendo desvendados por uma nova elite jurídica, que, até então, estava entregue ao quase adormecimento.

Diante desse cenário, o tema financiamento público educacional corre o risco de tornar-se ostentação, diante do discurso dominante de falência do Estado. Fato que caracteriza o mais perverso dos cenários para a Educação Pública Brasileira, pois sem financiamento não se faz Educação. O financiamento deve estar para a Educação da mesma forma que a água deve estar para a vida humana - uma condição essencial de sobrevivência.

Desponta uma sociedade que parece estar a cada dia mais desvalida financeira, cultural e politicamente. Discutir nesse momento o aumento ou mesmo a manutenção da vinculação de recursos públicos para uma determinada área orçamentária do Estado pode representar algum tipo de privilégio ostentador. Logo, pode transformar-se em um escândalo estampado nas manchetes sensacionalistas dos diversos meios de comunicação da nova mídia nacional.

Quando o povo, varrido por uma nuvem de desgraças sociais, começa a perder seus direitos básicos, perde, também, a sua liberdade de pensamento e reflexão. "[...] existe uma diferença entre ser 'livre de' e ser 'livre para'. Se você não for livre da fome, da falta de abrigo, da falta de socorro médico, você não é livre para outras escolhas" (CORTELLA, 2016, p. 22, grifos do autor).

Embora a Educação faça parte dos direitos básicos de uma sociedade, quando o desemprego, a fome e a miséria assolam uma parcela grande da população, há um alerta geral de sobrevivência que soa nos ouvidos estressados de toda a sociedade, deixando temas como a Educação à margem das discussões. Fato que só contribui para o aumento da crise instalada, pois não há espaço para reflexão coletiva sobre a situação. Poucos iluminados passam a pensar e agir em nome de muitos.

Para tratar dessa temática tão carente de discussão, este artigo adota uma abordagem qualitativa, com enfoque crítico, e tem, como base teórica de sustentação 
para a metodologia adotada, estudos sobre o tema desenvolvidos por teóricos como Chizzotti (2000, 2012), Denzin e Lincoln (2006).

\section{Histórico de luta}

Vincular recursos financeiros à Educação há muito representa uma luta da sociedade brasileira. Historicamente, as discussões que envolvem o tema do financiamento educacional passaram a fazer parte dos debates acadêmicos, políticos e populares com mais perceção e pressão quando a questão da vinculação de recursos públicos para a educação passou a ser discutida.

Em uma das ocasiões de discussões políticas sobre este tema, em 1997, o então Constituinte Florestan Fernandes recebeu o seguinte telegrama:

\footnotetext{
Os colégios católicos Juiz de Fora estranham Vossa Excelência favorável texto constitucional disposição discriminatória antidemocráticas verbas públicas somente para o ensino estatal, impossibilitando pessoa humana, sujeito principal educação, mesmo carente, escolher escola sua preferência, livre iniciativa ou estatal, manifestada por si ou responsável. (telegrama recebido pelo Constituinte Florestan Fernandes e transcrito em FERNANDES. Florestan. Educação e Constituição. Folha de S. Paulo. 04 de agosto de 1997, p. A-3). (FARENZENA, 2006, p. 111).
}

Essa citação evidencia o desconforto e a pressão de organizações privadas educacionais devido à vinculação de recursos públicos à Educação ser direcionada apenas às escolas públicas. Tema discutido durante a Assembleia Nacional Constituinte (1987-1988) que resultou, após muita discussão, com garantia legal, a vinculação dos recursos públicos, representados por impostos próprios de cada esfera de Governo, à Educação brasileira.

Há muito já se pensava em vincular recursos públicos à Educação pública. Segundo Melchior (1981), uma proposta de Lei para estabelecer um mínimo das receitas públicas à Educação veio por meio do senador João Alfredo. Ainda, durante a revisão constitucional de 1925-1926, foi apresentada uma proposta de vinculação constitucional de recursos públicos para a Educação, que não chegou a ser apreciada pelo poder público.

A primeira vez que esse tema apareceu legalmente, fruto de discussão pública, foi na Constituição de 1934, provocada pela luta dos chamados pioneiros da educação nova, representados por nomes como Fernando de Azevedo, Anízio Teixeira, Paschoal Leme, entre outros. O Quadro 1 a seguir demonstra, historicamente, as alíquotas da vinculação de recursos para a educação no Brasil. 
Quadro 1 - Alíquotas de vinculação de recursos para a Educação pública no Brasil

\begin{tabular}{|c|c|c|c|c|}
\hline Ano & Disposições Legais & União & Estado/ DF & Municípios \\
\hline 1934 & Constituição Federal & $10 \%$ & $20 \%$ & $10 \%$ \\
\hline 1937 & Constituição Federal & Nenhuma & Nenhuma & Nenhuma \\
\hline 1942 & Decreto Lei 4.958 & Nenhuma & 15 a $20 \%$ & 10 a $15 \%$ \\
\hline 1946 & Constituição Federal & $10 \%$ & $20 \%$ & $20 \%$ \\
\hline 1961 & $\begin{array}{c}\text { LDB - Lei de Diretrizes e } \\
\text { Bases da Educação Nacional } \\
4.024\end{array}$ & $12 \%$ & $20 \%$ & $20 \%$ \\
\hline 1967 & Constituição Federal & Nenhuma & Nenhuma & Nenhuma \\
\hline 1969 & $\begin{array}{c}\text { Emenda Constitucional- EC- } \\
1\end{array}$ & Nenhuma & Nenhuma & $20 \%$ \\
\hline 1971 & LDB 5.692 & Nenhuma & Nenhuma & $20 \%$ \\
\hline 1983 & EC 14 & $13 \%$ & $25 \%$ & $25 \%$ \\
\hline 1988 & Constituição Federal & $18 \%$ & $25 \%$ & $25 \%$ \\
\hline
\end{tabular}

Fonte: elaborado pela autora com base em Oliveira (2007, p. 92).

Um estudo do Quadro 1 evidencia uma grande dificuldade na vinculação de recursos para a Educação. Em alguns momentos históricos, nenhuma esfera do Governo comprometeu-se com o tema, já, em outros, poucas esferas comprometeramse sozinhas, tornando o financiamento educacional deficitário. A União é a que menos se comprometeu com a vinculação de recursos.

No ano de 1996, com o advento do Fundo de Manutenção e Desenvolvimento do Ensino Fundamental e de Valorização do Magistério (FUNDEF), que tinha como objetivo a universalização do Ensino Fundamental, equidade nos gastos por aluno do referido ensino, elevação dos salários do magistério do ensino público e melhoria da qualidade de Educação, a questão da vinculação de recursos à educação ganhou força, contando financeiramente com a subvinculação de $15 \%$ dos impostos destinados à Educação - Artigo 212 da Constituição Federal (BRASIL, 1988). Essa percentagem considerou que, a partir da vinculação inicial, a esfera governamental que recebeu o recurso transformaria o percentual recebido em 100\% de sua receita, aplicando 50\% e, posteriormente, $60 \%$ dos recursos vinculados ao Ensino Fundamental - Emenda Constitucional No 14 (BRASIL, 1996). Sobre essa Emenda Constitucional, Oliveira (2007) afirma:

Transformada pela propaganda governamental e pela conivência da mídia, em iniciativa federal de priorização do ensino fundamental, este artigo é uma obraprima de ilusionismo jurídico-político. Ao mesmo tempo que aumenta os recursos a serem aplicados no ensino fundamental por parte de estados, Distrito Federal e municípios (de $50 \%$ para $60 \%$ dos recursos vinculados), silencia sobre as responsabilidades da União com ele relacionadas, colocando-a em 
situação explicitamente secundária em relação aos outros níveis da administração pública. (OLIVEIRA, 2007, p. 109).

A respeito do FUNDEF, os pesquisadores da área educacional concordam com o descompromisso da União, dada pela parcela de vinculação ${ }^{11}$ e a priorização do Ensino Fundamental em detrimento da Educação Infantil, Ensino Médio e Educação de Jovens e Adultos, comprometendo o sucesso do Fundo. A questão da universalização do Ensino Fundamental e da equidade nos gastos por aluno, que foi vista por alguns administradores públicos, principalmente os municipais, como fonte adicional de renda, propiciou um processo intenso de municipalização, visto que a distribuição do fundo levou em consideração o número de alunos matriculados no Ensino Fundamental. A Educação passou a ser vista como um bom negócio pelos municípios.

Os impostos vinculados ao FUNDEF vinham do ICMS, FPE, FPM, IPI exportação e compensação financeira da Lei Complementar 87/96 ${ }^{12}$. Mais tarde, o FUNDEF tornou-se Fundo de Manutenção e Desenvolvimento da Educação Básica e de Valorização dos Profissionais da Educação (FUNDEB), representando um avanço qualitativo para a Educação Básica brasileira, pois não se beneficiava mais tão somente o Ensino Fundamental, mas toda a Educação Básica. O percentual de subvinculação aumentou, de $15 \%$ para $20 \%$, tendo o acréscimo ainda de outros impostos como ITCD, IPVA e ITR (cota federal). A Educação passou a representar um bom negócio para muitos.

A garantia de continuidade da vinculação de recursos financeiros à Educação continuou motivo de luta acadêmica, política e popular durante toda a história que se segue após a publicação do FUNDEB. Alguns economistas e políticos utilizavam-se da linguagem do economês para defender o fim da vinculação, afirmando que havia muito recurso financeiro aplicado na Educação, porém malgasto. De outro lado, os que eram a favor da vinculação defendiam a necessidade de mais recursos financeiros, apontando salários desfasados, escolas sucateadas e alunos desmotivados, com alto índice de abandono escolar e péssimo rendimento educacional.

Vale ressaltar, que a Emenda Constitucional no 53, de 19/12/2006, que criou o FUNDEB, estabeleceu o prazo de 14 anos, a partir de sua promulgação, para sua vigência. Logo, no ano de 2020, teremos que rediscutir suas regras e continuidade. De

\footnotetext{
11 "Ao final da vigência do FUNDEF, a União acumulava uma dívida superior a 25 bilhões de reais com os fundos estaduais e com o Ensino Fundamental das regiões mais pobres do país" (EDNIR; BASSI, 2009, p. 103).

12 Lei Kandir - Lei Federal que isenta do tributo - ICMS - os produtos e serviços destinados à exportação. A Lei pega emprestado o nome de seu autor, o ex-Deputado Federal Antonio Kandir.
} 
sua permanência depende nossa Educação Pública, sua proposição permanente, como política

financiamento da Educação Básica, deve ser nosso foco.

\section{A dimensão do gasto em Educação}

No ano de 2012, iniciaram-se discussões a respeito do percentual do $\operatorname{PIB}^{13}$ que deveria ser investido em Educação. A Emenda Constitucional de n ${ }^{\circ}$ 59, de 11 de novembro de 2009, determinara que, no próximo Plano Nacional de Educação (PNE), houvesse uma conjugação do PIB com a Educação (BRASIL, 2009). Dessa forma, na Conferência Nacional de Educação (CONAE), do ano de 2010, decidiu-se como meta o investimento de $10 \%$ do PIB até 2020.

A Câmara Federal aprovou, no ano de 2012, uma meta de investimento público de $10 \%$ do PIB para a Educação pública, a ser atingida no prazo de dez anos. Parecia que o final feliz estava próximo. No decorrer de 2014, houve a publicação do Plano Nacional de Educação (2014/2024), que previu um progressivo aumento de investimento público em educação a ser avaliado no quarto ano de vigência do Plano, podendo ser ampliado por lei (BRASIL, 2014). Há citação ainda no mesmo documento, do progressivo investimento vir da exploração do petróleo retirado da recém-descoberta camada do pré-sal, que, segundo o discurso político dominante da época, era algo promissor e levaria o país ao primeiro mundo. O que instigava a população e aquecia as discussões acadêmicas era a dúvida que rondava o fato de se haveria realmente recurso financeiro para manter essa determinação legal ou até aumentá-la.

A resposta veio rápida. Antes mesmo de ter tempo para reflexões mais profundas sobre o tema, o Ministro da Fazenda, Sr. Henrique Meirelles (Gestão 2017), declara haver necessidade urgente de cortar gastos orçamentários. Amparado por esse discurso, uma medida de corte radical de gastos foi assinada pelo então Presidente da República Sr. Michel Temer, a PEC do Teto dos Gastos $^{14}$. Estava decretada a estagnação dos investimentos públicos em diversas áreas, sendo uma delas, a Educação. Aquela que, ilusoriamente há pouco havia ensaiado um simbólico final quase feliz, estava mais uma vez entregue a um futuro incerto.

Os recursos destinados à Educação são determinados legalmente e estão

${ }^{13}$ PIB é a sigla para Produto Interno Bruto e representa a soma, em valores monetários, de todos os bens e serviços finais produzidos em uma determinada região, durante um determinado período.

${ }^{14}$ Emenda Constitucional no 95 , que limita por 20 anos os gastos públicos. 
expressos no Artigo 68 da Lei de Diretrizes e Bases da Educação Nacional (LDB) 9.394/96, sendo originários da receita de impostos próprios da União, Estados, Distrito Federal e dos Municípios; transferências constitucionais e outras transferências; salário-educação e contribuições sociais; incentivos fiscais além de outros recursos previstos em Lei.

$\operatorname{Art}^{\circ}$. 69. A União aplicará, anualmente, nunca menos de dezoito, e os Estados, o Distrito Federal e os Municípios, vinte e cinco por cento, ou o que consta nas respetivas Constituições ou Leis Orgânicas, da receita resultante de impostos, compreendidas as transferências constitucionais, na manutenção e desenvolvimento do ensino público. (BRASIL, 1996).

Para conferir se a União, os Estados e os Municípios têm aplicado, na Educação Pública, o percentual previsto em lei, uma das alternativas é uma busca nos diversos Portais governamentais de Transparência disponíveis online e abertos à consulta pública. No caso da União, uma consulta ao Portal da Transparência da Controladoria Geral da União $(\mathrm{CGU})^{15}$ pode ser uma alternativa válida. Legalmente, é um local onde a população deveria visualizar com facilidade os gastos do Governo Federal nas diversas áreas orçamentárias.

Considerando que este texto tem como premissa as questões orçamentárias federais relacionadas à Educação, atentar-nos-emos aos números da União. Em consulta ao Portal da Transparência da CGU, na área educacional - execução orçamentária - tomando como base o intervalo temporal de 2004 a 2014, os números ficam mais evidentes nos anos de 2009, 2013 e 2014. Nos outros anos, a linguagem orçamentária utilizada torna difícil uma consulta detalhada quanto à execução orçamentária anual. A mesma consulta realizada no portal do Ministério da Educação torna ainda mais difícil a busca por dados orçamentários anuais. Eles são disponibilizados de forma fragmentada, não demonstrando a execução orçamentária total por ano.

Essa procura cansativa e, por vezes, sem sucesso por dados orçamentários federais da área educacional, evidencia a existência de uma maquiagem numérica instalada, que resulta em dificuldade de leitura dos documentos oficiais em geral e, principalmente, a dos orçamentários, pois a linguagem utilizada é própria da área contábil pública, que a maioria da população desconhece. "O governo consegue ser transparente em relação à execução do orçamento, sem o ser" (EDNIR; BASSI, 2009, p. 153).

Uma nova busca, desta vez no Portal do Senado Federal, parece ter tido mais

\footnotetext{
${ }^{15}$ Disponível em: <http://www.cgu.gov.br/>. Acesso em: 13 maio 2017.
} 
sucesso. Há um Boletim Legislativo nº 26 que demonstra as despesas em Educação no período de 2004 a 2014, assinado pelo então consultor legislativo do Senado, Sr. Marcos Mendes:

Nota-se que, de fato, a despesa quase quadruplicou no período em termos reais, passando de $\mathrm{R}$ \$ 24,5 bilhões em 2004 para R \$ 94,2 bilhões em 2014, o que equivale a 1,71\% do PIB (em proporção do PIB o aumento foi de 2,3 vezes). (R\$ Bilhões de 2014 e \% do PIB) - Despesa do Governo Federal na Função Educação: 2004 a 2014. (MENDES, 2015, p. 2).

O Boletim demonstra uma evolução anual considerável de despesas para a área educacional, porém bem abaixo dos $10 \%$ do PIB previstos no PNE. Ainda no mesmo documento, o autor salienta o fato de a União ter, no período pesquisado, ultrapassado por vários anos o montante mínimo de despesa obrigatório em Educação. "Somente nos três últimos anos da série (2012-2014) a União gastou $\mathrm{R} \$ 43,1$ bilhões acima do limite mínimo (uma média de R $\$ 14,4$ bilhões a mais por ano) [...]" (MENDES, 2015, p. 2).

Ao considerar a evidência de aumento gradativo anual de despesas no período pesquisado, com gastos acima do limite imposto por lei, combinada à publicação da Emenda Constitucional $n^{\circ} 95$, que resulta na estagnação dos investimentos públicos em Educação, confirma-se o pior cenário financeiro para a Educação Pública Brasileira, o de recessão educacional, ou seja, retração geral da atividade de aquisição de conhecimento. Em uma recessão econômica, cortam-se gastos; em uma recessão educacional, corta-se a possibilidade de formarem-se sujeitos, entendendo este último como alguém capaz de refletir e interferir sobre uma determinada sociedade.

\section{Interesses conflituosos}

E agora? Qual o destino das discussões que envolvem a vinculação de recursos para a Educação Pública e a própria existência de financiamento público educacional? Considerando a atual Nação Democrática Brasileira, talvez esse questionamento deva ser analisado refletindo sobre se há interesse do Estado em discutir publicamente o tema e mesmo em financiar plenamente a Educação Pública nesse momento.

Pondé (2016), ao comentar sobre o atual regime democrático brasileiro, chama a atenção para a condução tendenciosa que a tem acompanhado, passando a representar mais uma forma de manipulação das massas do que um espaço de reflexão coletiva. 
opiniões a serem defendidas (compradas) ou recusadas (não compradas). A tendência da mentira na democracia é, no limite, uma tendência ao marketing. (PONDÉ, 2016, p. 133).

Uma democracia enfraquecida, uma escola pública empobrecida financeiramente e, por consequência, prejudicada em sua capacidade de produção do conhecimento, são cenários propícios para o surgimento de uma sociedade alienada, que se inclina a comprar opiniões marqueteiras que se apresentam como uma "[...] falsa consciência que distorce o quadro que temos da realidade social e serve aos interesses da classe dominante de uma sociedade" (APPLE, 2006, p. 53). Vale ressaltar que não está aqui sendo citado e colocado em dúvida o Sistema Democrático como opção de organização política de um país, mas sim o momento democrático vivido hoje no Brasil.

Há algumas pesquisas acadêmicas que apontam para o fato de até 2050 termos uma diminuição de $40 \%$ no número de crianças em idade escolar ${ }^{16}$, colocando o Brasil, em longo prazo, em condição mais favorável, considerando a demanda escolar e o financiamento público educacional. Levando em consideração essas pesquisas e a luta enfraquecida para aumento do PIB investido em Educação, conclui-se que essa condição pode demorar muito a ocorrer ou que não aconteça, visto que, para o futuro, é prevista uma situação de mais conforto para as crianças que ingressarão nos primeiros níveis da Educação, sem a necessidade de aumento dos investimentos públicos. Essa conclusão perigosa censura os cérebros de nossos estudantes hoje e engrossa o coro dos chamados por Pondé (2016) de "aduladores de idiotas", fruto de um discurso pautado na existência de um cenário de recessão financeira. Condena, ainda, toda a sociedade em um futuro próximo, por colocar em dúvida a formação de nossos vindouros líderes.

Como se todo esse turbilhão social e econômico não bastasse, há, ainda, no cenário nacional, o aparecimento de escândalos de corrupção financeira, que, segundo as últimas investigações realizadas e conduzidas por membros da mais conspícua magistratura nacional, parece ter devorado uma parte considerável de recursos financeiros que poderiam ter sido previstos e executados no Orçamento Público de todas as esferas governamentais.

\footnotetext{
${ }^{16}$ Há, portanto, uma redução da população educacional em idade de 84,4 milhões, em 2008, para 50,9 milhões, em 2050, o que representa uma redução de 40\%. Há uma importante queda de 44\%, em 2008, para $24 \%$, em 2050, do percentual da população brasileira em idade educacional em relação à população total brasileira. Esse fato justificaria uma queda natural na necessidade de financiamento como percentual do PIB, de 2020 para 2050. (AMARAL, 2012, p. 195).
} 
Percebe-se que, mesmo havendo fiscalização de gastos, com a obrigatoriedade de prestações de contas oficiais, sujeitas à aprovação ou não de órgãos centrais que apenas conferem papéis oficiais juntados em uma determinada ordem, há uma rede invisível instituída que suga o orçamento público e se favorece dele.

A invisibilidade desta rede de corrupção se instala e se fortalece na atitude de consentimento dos envolvidos, mesmo não concordando inteiramente. Fazemse de cegos, suspeitam ou até mesmo presenciam, mas com a cultura do abafa, deixam-se vencer. Quem vê não denuncia; quem ouve, faz-se de surdo; quem fala, desmente depois. O medo mescla-se à covardia e vence o mais forte (BOCCHI, 2015, p. 128).

É preciso urgentemente derrubar essa cultura instituída, lutar pela ética financeira, enfrentar esses abismos sem se deixar cair. E uma das principais formas de destruição gradativa dessa rede é a discussão do tema Financiamento Público Educacional pelos diversos cantos do país.

\section{Considerações}

A inclusão do estudo e a discussão de questões que envolvem o Financiamento Público Educacional entre alunos, professores e toda a comunidade escolar é urgente e necessária, para que deixe de ser um tema distante, árido e passe a ser um tema de abordagem cotidiana em todas as escolas, tendo como objetivo a formação de futuros líderes educacionais, conscientes da questão financeira em seus aspetos teóricos, históricos e técnicos, em uma perspetiva crítica e criativa. Paralelamente à discussão orçamentária, é necessário, também, discutir a Educação Pública Brasileira como um todo, para que tenhamos a oportunidade de enriquecer o discurso governamental, estabelecer um diálogo possível, tendo como base a consulta popular, a audição atenta dos envolvidos e uma devolutiva responsável, democrática e compromissada com o desenvolvimento de uma educação de base sólida, que não seja entendida como "bem e serviço mercantis, sujeitos às leis de mercado, ou eufemisticamente, quase-mercado" (CHIZZOTTI, 2012, p. 447)

Entre os temas educacionais discutidos, alguns tornam-se urgentes, como a construção de novas escolas que possam acomodar os alunos que ainda superlotam as salas de aula e dificultam o trabalho educacional; substituição definitiva das escolas construídas com materiais provisórios e frágeis por construções de alvenaria que permitam reverter a condição de abandono intelectual de seus alunos; obras de manutenção e expansão escolar que realmente contemplem as reais necessidades da escola e melhores condições salariais para os profissionais da Educação Pública, para 
que possam se dedicar a jornadas de trabalho mais humanas e possíveis. Para que essas condições sejam plenamente garantidas, é necessário que haja o envolvimento dos sujeitos no processo educacional, participando e decidindo sobre as políticas públicas a serem implantadas pelo Estado.

Essa participação está condicionada à vontade do querer, de envolver-se nas questões financeiras educacionais, fundamental para uma atuação mais pontual nos assuntos que abarquem o financiamento da Educação, de forma a valorizar a formação de Conselhos e de Associações que realmente fiscalizem e tenham voz de decisão sobre os gastos educacionais. Além disso, que briguem pela descentralização de verbas públicas destinadas a setores que exijam urgência de atitudes, para que a escola possa dar continuidade ao seu trabalho em tempo que não cause prejuízo em seus dias letivos.

O querer e o envolver-se são condições primordiais para que ocorra participação popular no processo educacional. Representam a base da luta por uma Política Pública de Estado para a Educação, em que a hegemonia dominante possa ser contestada pelos então empodeirados sujeitos educacionais, plenamente inteirados das questões financeiras pertinentes, interferindo desde o seu plano orçamentário até seu gasto real com o aluno, "[...] a formação da hegemonia não pode ser separada da produção da ideologia". (DENZIN; LINCOLN, 2006, p.282)

Ao Estado cabe, se de fato estiver compromissado com seu discurso para a Educação, rever o processo de burocratização, permitindo a existência desses sujeitos, capazes de contribuir de maneira consciente, crítica e atuante no processo educacional do Estado. Confiando a Educação a quem lhe é de direito e não nas mãos de alguns poucos que a têm como uso de poder ou para possíveis favorecimentos ilícitos.

As questões que envolvem o financiamento educacional, embora equivocadamente pareçam distantes, necessitam ser estudadas e compreendidas em todas as suas dimensões, "numa interdependência viva entre sujeito e objeto, um vínculo indissociável entre o mundo objetivo e a subjetividade do sujeito" (CHIZZOTTI, 2000, p. 79). Estudo esse fundamental para que uma Educação vista pela lente econômica possa ser combatida por uma Educação de fato pautada na formação do sujeito crítico e reflexivo.

Se a relação entre financiamento público e educação persistir como se encontra e não for assumida e discutida criticamente pelos educadores, entendida $\mathrm{e}$ levada a sério, considerando os aspetos políticos voltados à Educação, desencadearse-á, de forma mais brutal, uma relação que já está fragilizada, entregue aos mandos e aos desmandos de uma política de Governo, em que o mais importante é o crescimento econômico do Estado. 
Pensando nos desafios aqui abordados, registro duas premissas, que devem ladear o tema Financiamento da Educação Pública:

- Financiamento Público para quem?

- Quem são os financiados?

O Primeiro, por não se ter claro até hoje a quem objetivou tantos recursos. O segundo, por considerar um universo de financiados obscuro. Tantos sujeitos fizeramse presentes, mas distantes do sujeito aluno. A finalidade dessas duas questões é fundamental para entender a qualidade de Educação que buscamos e a qualidade em que ela se encontra. 

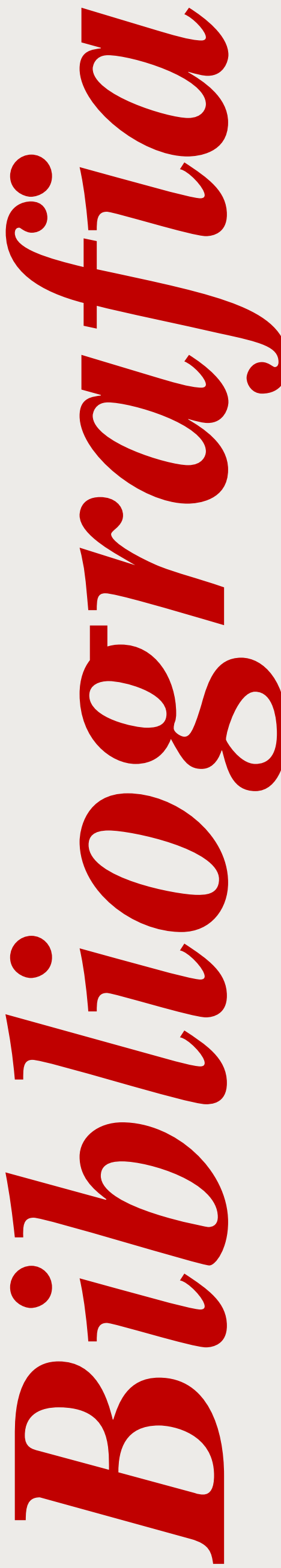

AMARAL, N. C. Para compreender o financiamento da educação básica no Brasil. Brasília: Liber Livro, 2012.

APPLE, M. W. Ideologia e currículo. Porto Alegre: Artmed, 2006.

BOCCHI, R. M. B. O financiamento público do Estado de São Paulo para a Educação Básica pública estadual: os desafios das controvérsias (Gestão 2008-2012). 2015. 261 f. Tese (Doutorado em Educação: Currículo) - Pontifícia Universidade Católica, São Paulo, 2015.

BRASIL. Constituição (1988). Constituição da República Federativa do Brasil. Brasília, DF: Senado, 1988.

BRASIL. Emenda Constitucional No 14, de 12 de setembro de 1996. Diário Oficial [da] República Federativa do Brasil, Congresso Nacional, Brasília, DF, 13 set. 1996. Seção 1, no 179, p. 18109-18110.

BRASIL. Emenda Constitucional No 59, de 11 de novembro de 2009. Diário Oficial [da] República Federativa do Brasil, Congresso Nacional, Brasília, DF, 12 nov. 2009. Seção 1, no 216, p. 8.

BRASIL. Lei N 9.394, de 20 de dezembro de 1996. Estabelece as diretrizes e bases da educação nacional. Diário Oficial [da] República Federativa do Brasil, Poder Legislativo, Brasília, DF, 23 dez. 1996. Seção 1, no 248, p. 27833-27841.

BRASIL. Lei N ${ }^{\circ}$ 13.005, de 25 de junho de 2014. Aprova o Plano Nacional de Educação - PNE e dá outras providências. Diário Oficial [da] República Federativa do Brasil, Poder Legislativo, Brasília, DF, 26 jun. 2014. Seção 1, no 120-A, edição extra, p. 1-7. 2000 .

CHIZZOTTI, A. Pesquisa em ciências humanas e sociais. São Paulo: Cortez,

CHIZZOTTI, A. Currículo por competências: ascensão de um novo paradigma curricular. Educação e Filosofia, Uberlândia, v. 26, n. 52, p. 429-448, jul./dez. 2012.

CORTELLA, M. S. Por que fazemos o que fazemos? aflições vitais sobre trabalho, carreira e realização. São Paulo: Planeta, 2016.

DENZIN, N. K.; LINCOLN, S. L. O planejamento da pesquisa qualitativa: teorias e abordagens. Porto Alegre: Artmed, 2006.

EDNIR, M.; BASSI, M. E. Bicho de sete cabeças: para entender o financiamento da educação brasileira. São Paulo: Peirópolis: Ação Educativa, 2009.

FARENZENA, N. A política de financiamento da educação básica: rumos da legislação brasileira. Porto Alegre: UFRGS, 2006.

MELCHIOR, J. C. A. A política de vinculação de recursos públicos e o financiamento da educação no Brasil. São Paulo: FEUSP, 1981.

MENDES, M. J. A despesa federal em Educação: 2004-2014. Brasília: Núcleo de Estudos e Pesquisas/CONLEG/Senado, abril/2015 (Boletim Legislativo $n^{\circ} 26$, de 2015). Disponível em: <www.senado.leg.br/estudos>. Acesso em: 10 maio 2017.

OLIVEIRA, R. P. Gestão, financiamento e direito à educação: análise da Constituição Federal e da LDB. São Paulo: Xamã, 2007.

PONDÉ, L. F. Filosofia para corajosos. São Paulo: Planeta, 2016 